Volume 1, Nomor 2, Oktober 2020, 67-74

JTTM: Jurnal Terapan Teknik Mesin

p ISSN 2721-5377 | e ISSN 2721-7825

\title{
PERAWATAN DIES NOMOR PRODUKSI 1177 (A) PADA MESIN PRESS AIDA 75 TON DI PT. $X$
}

\section{MAINTENANCE DIES PRODUCTION NUMBER 1177 (A) ON 75 TON AIDA PRESS MACHINE IN PT. $X$}

\author{
Teguh Supriyanto $^{1 *}$, Wisnu Pracoyo ${ }^{2}$, Hilman Sholih ${ }^{3}$ \\ 1,2,3 Program Studi Teknik Mesin, Sekolah Tinggi Teknologi Muhammadiyah Cileungsi \\ Jl. Anggrek No. 25, Perum PTSC, Cileungsi, Bogor, Jawa Barat, Indonesia 16820 \\ *Koresponden Email: t.supriyanto1990@gmail.com
}

\begin{abstract}
Abstrak. Globalisasi membuat persaingan dunia usaha di segala bidang sangat ketat. Konsumen hari ini semakin punya banyak pilihan. Setiap perusahaan dituntut untuk selalu melakukan tindakan terbaik jika tidak ingin ditinggalkan pelanggan. Kelancaran proses produksi adalah salah satu hal penting agar perusahaan bisa memenuhi harapan pelanggan baik dari sisi kualitas maupun waktu pengiriman. Faktor yang sangat penting untuk memenuhinya adalah kondisi mesin dan tools yang baik. Untuk itu diperlukan tindakan perawatan. Penelitian ini bertujuan untuk untuk mendapatkan gambaran langkah-langkah perawatan dies nomor produksi 117(A) pada mesin press AIDA 75 ton di PT. X. Metode yang digunakan dalam penelitian ini dengan melakukan wawancara beberapa personal yang terkait obyek penelitian, melakukan identifikasi dan literatur review. Simpulan yang didapat dari penelitian ini adalah bahwa perawatan dies nomor produksi 1177(A) pada mesin press AIDA 75 ton di PT. X terdiri dari 4 proses, yaitu proses Checking, proses Grinding, proses Cleaning dan proses Assembling.
\end{abstract}

Kata kunci: Manufaktur, Perawatan, Produksi

\begin{abstract}
Globalization has made competition for the business world in all fields very tight. Consumers today have more and more choices. Every company is required to always do the best action if customers do not want to be abandoned. The smooth running of the production process is one of the important things so that the company can meet customer expectations both in terms of quality and delivery time. A very important factor to fulfill it is the condition of the machine and good tools. This requires treatment. This study aims to obtain an overview of the maintenance steps for dies production number 117 (A) on the 75 ton AIDA press machine at PT. X. The method used in this research is by conducting interviews with several personnel related to the research object, identifying and reviewing literature. The conclusion from this research is that the maintenance of dies production number 1177 (A) on AIDA 75 ton press machine at PT. X consists of 4 processes, namely the Checking process, the Grinding process, the Cleaning process and the Assembling process.
\end{abstract}

Keywords: Manufacturing, Maintenance, Production

\section{PENDAHULUAN}

Persaingan di dunia usaha di segala bidang sangat ketat. Konsumen hari ini semakin punya banyak pilihan. Perusahaan dituntut untuk menunjukkan keunggulan dibandingkan pesaing. Salah satu cara agar perusahaan dapat memuaskan konsumen dengan mempertahankan dan meningkatkan kualitas produk dan layanannya [1]. Kelancaran proses produksi merupakan salah satu faktor penunjang keberhasilan industri manufaktur di dalam menghadapi persaingan [2]. Apabila proses produksi lancar, maka akan menghasilkan produk yang berkualitas, waktu produksi yang tepat dan ongkos produksi yang murah. 
Manusia, mesin atau sarana penunjang lainnya menjadi hal yang penting dalam mencapai keberhasilan proses produksi.

Perawatan mesin dan peralatan penunjang produksi merupakan kegiatan yang sangat diperlukan dalam kegiatan produksi. Kondisi yang siap pakai dari mesin dan peralatan, dapat dijaga dan ditingkatkan kemampuannya dengan menerapkan program perawatan yang terencana, teratur dan terkontrol. Perawatan mesin yang baik dapat meningkatkan keandalan dan performa mesin. Oleh karena itu, aktivitas perawatan merupakan bagian penting dari suatu industri untuk meningkatkan produktivitas dan efisiensi [3].

Dalam usaha untuk dapat terus menggunakan fasilitas produksi agar kontinuitas produksi dapat terjamin, maka di rencanakanlah kegiatan perawatan yang dapat menunjang keandalan suatu mesin atau fasilitas produksi. Keandalan mesin dan fasilitas produksi merupakan salah satu aspek yang dapat mempengaruhi kelancaran proses produksi serta produk yang dihasilkan [4]. Penurunan kondisi mesin dapat berpengaruh besar terhadap proses produksi. Kegiatan perawatan mesin sangat diperlukan untuk mengatasi permasalahan kegagalan fungsi suatu alat [5].

Perawatan adalah kegiatan yang dilakukan untuk mencapai hasil yang mampu mengembalikan atau mempertahankan sebuah peralatan pada kondisi yang selalu dapat berfungsi dengan baik [6]. Selain itu perawatan merupakan pekerjaan rutin, pekerjaan yang berulang-ulang, diperlukan untuk menjaga fasilitas yang ada agar tetap dalam keadaan baik, dapat digunakan sesuai dengan kapasitas dan efisiensi semula.

Dari penjelasan sebelumnya maka dapat disimpulkan bahwa kegiatan pemeliharaan atau perawatan adalah kegiatan merawat atau memperbaiki peralatan perusahaan agar dapat melakukan proses produksi dengan efektif dan efisien sesuai dengan pesanan yang telah direncanakan dengan hasil produk yang berkualitas. Perawatan atau maintenance dalam dunia industri sudah menjadi bagian yang wajib dan mutlak untuk dilakukan oleh setiap perusahaan. Hal ini dilakukan untuk mengurangi angka kerugian akibat rusaknya mesin-mesin serta alat penunjang produksi lainnya.

Dalam industri manufacturing yang dijalankan oleh PT. X tingkat ketepatan dan ketelitian suatu produk sangatlah penting dengan part NG (Not Good) atau reject mendekati nol. Untuk itu dibutuhkan mesin dan peralatan (tools) yang mempunyai ketelitian dan ketepatan yang baik. Salah satu upaya untuk mempertahankan kondisi ini adalah dengan cara melakukan pemeliharaan mesin dan peralatan penunjang produksi atau sering juga disebut maintenance. Maintenance ini mencakup perbaikan atau repair dan pemeliharaan secara berkala.

Salah satu bagian di PT. X yang menggunakan mesin sebagai alat penunjang produksi di departemen produksi press. Di bagian ini terdapat mesin-mesin press yang menggunakan dies sebagai peralatan penunjang produksinya.

Dies adalah benda esensial dalam industri manufaktur untuk mencetak benda menggunakan mesin press sebagai gaya tekan yang membentuk plat. Dies dapat dipakai berulang dengan penyesuaian bentuk 
yang tetap untuk produksi dalam skala besar dengan dimensi yang sama dan toleransi yang tidak jauh berbeda [7].

Dies terkadang yang menimbulkan masalah pada saat produksi berlangsung karena akibat pemasangan yang tidak benar dan tumpul atau aus akibat proses produksi yang terus-menerus. Untuk mencegah terjadinya kerusakan pada dies yang bisa berdampak pada berhentinya proses produksi, maka harus dilakukan perawatan secara berkala kepada dies. Berdasar latar belakang di atas, maka perlu diadakan penelitian untuk mengetahui langkah-langkah perawatan dies nomor produksi 1177 (A) pada mesin press AIDA 75 ton di PT. X .

\section{METODE}

Penelitian yang dilakukan adalah penelitian deskriptif yaitu sebuah penelitian untuk membuat deskripsi, gambaran atau lukisan sistematis, faktual dan akurat mengenai fakta-fakta, sifat-sifat serta hubungan antar fenomena yang diselidiki [8]. Dalam hal ini penelitian yang dilakukan adalah untuk mendapatkan gambaran langkah-langkah perawatan dies nomor produksi 117 (A) pada mesin press AIDA 75 ton di PT. X. Untuk mendapatkan gambaran yang jelas, dalam penelitian.

\subsection{Wawancara}

Wawancara adalah suatu bentuk komunikasi lisan yang dilakukan secara terstruktur oleh dua orang atau lebih, baik secara langsung maupun jarak jauh, untuk membahas dan menggali informasi tertentu guna mencapai tujuan tertentu pula [9]. Dalam penelitian ini pertanyaan ditujukan kepada beberapa responden yang terkait langsung dengan penggunaan dies nomor produksi 117 (A) pada mesin press AIDA 75 ton. Responden yang diambil dalam penelitian ini.

1. Operator Dies Shop, sebagai operator yang melakukan kegiatan perawatan dies 177(A).

2. Operator Produksi, sebagai operator yang menggunakan dies 1177 (A).

\subsection{Identifikasi}

Identifikasi terhadap trend kerusakan pada mesin produksi yang dioperasikan, supaya mendapatkan data untuk menurunkan trend kerusakan. Beberapa unsur yang muncul dalam fenomena di dalam objek yang diteliti. Hasil dari proses tersebut dilaporkan dengan laporan yang sistematis dan sesuai kaidah yang berlaku [10].

Dalam hal ini dilakukan identifikasi langsung di departemen engineering dan departemen produksi terhadap kegiatan yang berhubungan dengan operasional dies 117 (A).

\subsection{Literature Review}

Untuk mengetahui penelitian orang lain dalam bidang perawatan, serta meningkatkan kualitas penelitian, supaya bisa menentukan akar penyebab terhadap mesin press AIDA 75 ton.

\section{HASIL DAN PEMBAHASAN}

Dari penelitian yang dilakukan didapatkan bahwa langkah-langkah perawatan dies nomor produksi 
1177(A) pada mesin press AIDA 75 ton di PT.X.

\subsection{Proses Checking.}

Pemeriksaan mesin atau tools diawali dengan memperhatikan produk yang dihasilkan dan memeriksa kondisi mesin atau tools.

Berikut beberapa cara dalam pemeriksaan dies yang dilakukan.

A. Pemeriksaan kondisi part hasil produksi dies 1177 (A) proses pierching.

- Kondisi visual (bebas burry).

- Laporan OK/NG (Not Good) dari bagian Quality.

B. Pemeriksaan kondisi dies 1177 (A) proses pierching.

Pemeriksaan dies dilakukan dengan cara membongkar dies. Kemudian melakukan pengecekan satu-persatu bagian dies serta komponennya, terutama di bagian upper plate, lower plate, punch, punch holder, stripper, backing plate, die, stopper, guide post, dowel pin, spring, dan bolt. Alat bantu yang digunakan dalam proses pemeriksaan.
a) Kunci L (1 set).
b) Palu alumunium.
c) Tracker/crane.
d) Caliper.
e) Majun.

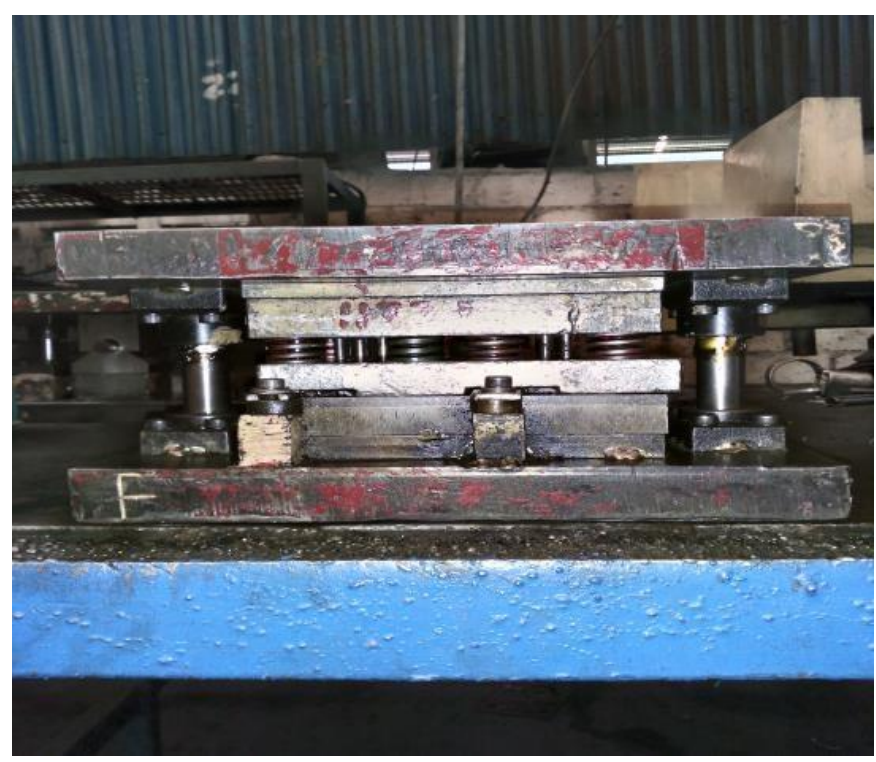

Gambar 1. Dies 1177(A) proses piercing 


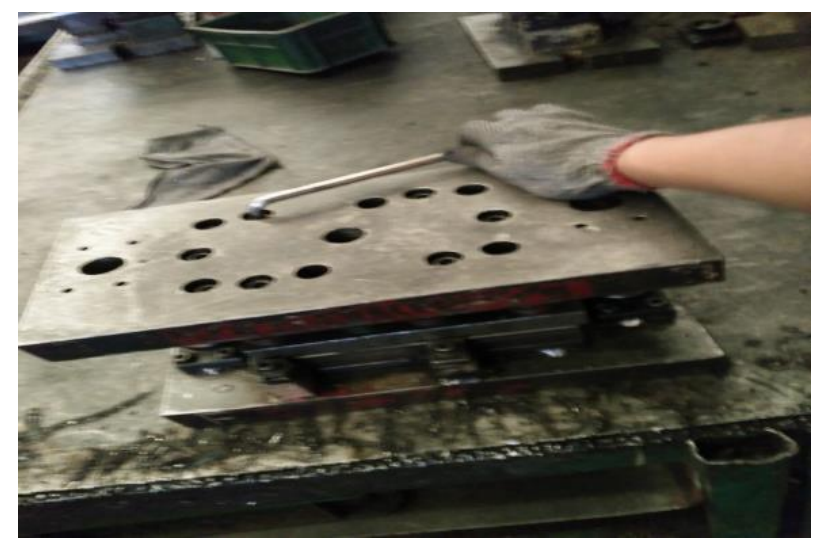

Gambar 2. Proses pembukaan bolt upper plate

\subsection{Proses Grinding}

Proses grinding adalah proses pengamplasan dengan batu gerinda dengan bantuan mesin grinding. Di bawah ini adalah mesin grinding yang digunakan di PT. X.

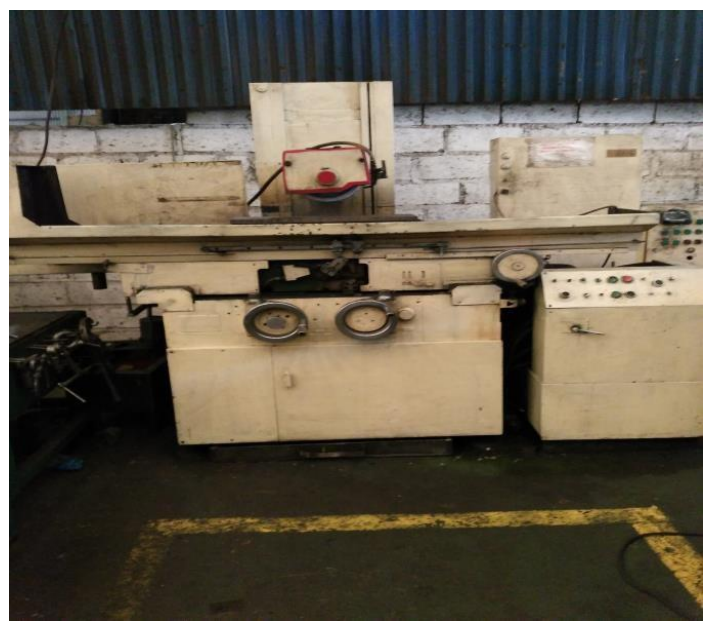

Gambar 3. Mesin grinding

Untuk proses grinding ada 3 macam, untuk menghasilkan suatu produk yang berkualitas.

A. Grinding Punch, yaitu menggrinding bagian punch atau pisau pemotong agar tajam kembali setelah proses produksi.

B. Grinding stripper, yaitu untuk meratakan permukaan stripper agar tidak terjadi lekukan pada saat proses pengepresan produk.

C. Grinding die base, untuk mempertajam die base yang sudah karat dan hole die base yang sudah besar akibat proses pierching.

Hal-hal yang perlu diperhatikan dalam proses grinding.

A. Total stroke dies

Total stroke dies adalah jumlah berapa kali dies tersebut melakukan pengepresan artinya setiap dies tersebut melakukan pengepresan maka semakin pendek pula umur pemakaiannya. Untuk mengetahui total stroke tersebut dapat dilihat dari output harian produksi atau control stroke dies. 
B. Pastikan kondisi mesin grinding $\mathrm{OK}$.

a) Cek batu gerinda jangan sampai ada patah atau permukaan tidak rata.

b) Magnet berfungsi dengan baik.

c) Air pendingin atau coolant berfungsi dengan baik.

C. Menggunakan APD dengan baik.
a) Masker
b) Sarung tangan
c) Kaca mata
d) Sepatu safety

Setelah kita mempersiapkan semuanya proses grinding siap untuk dikerjakan. Langkah-langkah dalam proses grinding.

1. Bongkar dies yang akan di grinding. Dalam proses grinding yang sekarang dilakukan adalah grinding punch yang tumpul.

2. Bersihkan upper plate, pastikan permukaan rata dan bersih.

3. Pastikan permukaan magnet mesin grinding kering dan tidak debu yang menempel.

4. Simpan upper plate di table magnet.

5. Pukul setiap sisi upper plate menggunakan palu aluminium (upper plate sudah menempel dengan stabil pada table magnet).

6. Nyalakan motor mesin grinding (batu grinding berputar).

7. Cari titik 0 antara upper plate dengan batu grinding untuk mencari titik awal untuk proses penggrindingan.

8. Lakukan proses grinding sampai bagian tumpul punch hilang (tidak ada ukuran yang ditentukan seberapa mm yang akan di grinding tetapi melihat secara visual tingkat ketajaman punch tersebut).

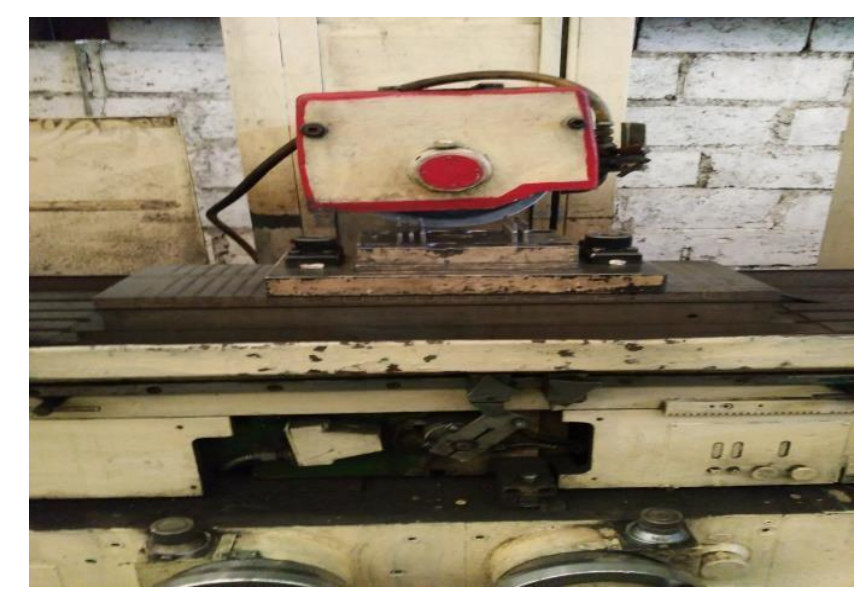

Gambar 4. Proses Penggrindingan Punch 


\subsection{Proses Cleaning}

Proses pembersihan dies dari debu, oli, minyak pelumas saat proses produksi, partikel, serta air coolant akibat proses grinding. Proses cleaning dilakukan agar dies tidak kotor serta tidak mudah berkarat. Alat bantu yang digunakan dalam proses cleaning.

1. Solar atau wash bensin.

2. Sikat.

3. Bambu stick.

4. Amplas $1000 \mathrm{CC}$.

5. Majun.

6. Air Gun.

\subsection{Proses Assembling}

Proses pemasangan kembali bagian-bagian dies serta komponennya. Pada proses assembling ini perlu diperhatikan bagian-bagian dan komponen dies tidak tertukar ataupun tidak terpasang, supaya pada saat unit dioperasikan bisa bekerja dengan normal.

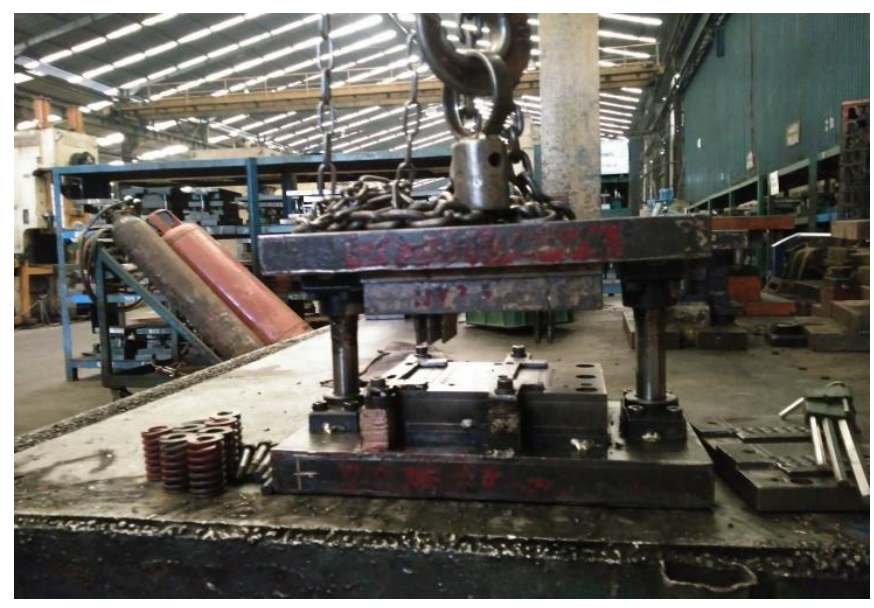

Gambar 5. Proses assembling dies

Setelah proses-proses perawatan dilakukan, untuk mengetahui histori pada alat adalah membuat laporan. Laporan perawatan dies di PT. X , 1) Buku history tooling dies, buku history tooling dies adalah dokumen yang berisi catatan total stroke, kerusakan yang terjadi pada dies dan perbaikan yang dilakukan pada dies tersebut dimulai dari dies itu masspro sampai dies tersebut dinyatakan discontinue. 2) Checklist preventive maintenance dies.

\section{SIMPULAN}

Perawatan pada mesin grinding untuk meminimalisasi kerusakan mesin, langkah yang harus dilakukan setiap manufaktur, 1. Routine maintenance yang meliputi dari pengecekan komponen yang bergerak, pelumasan, penggantian pelumas, 2. Predictive Maintenance yang sesuai untuk mesin produksi yang memiliki nilai besar, agar mendapatkan saving pada operating and maintenance. 


\section{DAFTAR PUSTAKA}

[1] M. Tjondrokusumo, "Analisa Faktor-Faktor Lingkungan Eksternal Sebagai Determinan Corporate Entrepreneurship Pada Industri Manufaktur Di Jawa Timur,” Agora, 2013.

[2] N. C. D. Dyah Ika Rinawati, “Analisis Penerapan Total Productive Maintenance (TPM) Menggunakan Overall Equipment Effectiveness (OEE) dan Six Big Losses pada Mesin Cavitec di PT. Essentra Surabaya," Pros. Semin. Nas. Teknol. dan Inform., 2014, doi: 10.32734/ee.v1i2.245.

[3] B. Kho, "Jenis-Jenis Maintenance (Perawatan) Mesin/Peralatan Kerja," https://ilmumanajemenindustri.com/, 2018. .

[4] M. Sayuti and M. dan Muhammad Siddiq Rifa, "Evaluasi Manajemen Perawatan Mesin Dengan Menggunakan Metode Reliability Centered Maintenance Pada PT. Z,” 2013.

[5] Sayuti and I. M, "Analisis Produktivitas Perawatan Mesin dengan Metode TPM ( Total Productive Maintenance ) Pada Mesin Mixing Section," Malikussaleh J. Mech. Sci. Technol. ISSN, 2016.

[6] D. S. Dhamayanti, J. Alhilman, and N. Athari, "USULAN PREVENTIVE MAINTENANCE PADA MESIN KOMORI LS440 DENGAN MENGGUNAKAN METODE RELIABILITY CENTERED MAINTENANCE (RCM II) DAN RISK BASED MAINTENANCE (RBM) DI PT ABC,” J. Rekayasa Sist. Ind., 2016, doi: 10.25124/jrsi.v3i02.29.

[7] E. Sutoyo and S. P. Sutisna, "Perancangan Dies Potong Dan Dies Tekuk Pada Press Brake," AME (Aplikasi Mek. dan Energi) J. Ilm. Tek. Mesin, 2017.

[8] Moh. Nazir, "Metode Penelitian,” Metod. Penelit., 2014, doi: 978-979-450-173-5.

[9] Maxmanroe, "Pengertian Wawancara Adalah, Tujuan, Jenis, Ciri-Ciri, Fungsi Wawancara," Maxmanroe.com, 2020. .

[10] R. Endra, "Pengertian Observasi menurut para ahli," Www.Ruangguru.Com, 2017. . 